\title{
Ler o 'sul' em viagem: Duas epistemologias literárias do sul global em Hinyambaan e em Um estranho em Goa
}

\author{
SHEILA KHAN \\ Machester University / Projecto Nação e Narrativa Pós-Colonial (Universidade Técnica de Lisboa)
}

\begin{abstract}
RESUMO: O PRESENTE ENSAIO ANALISA COMO AS DESLOCAÇÕES E AS VIAGENS SÃO CRIADORAS DE MOVIMENTOS NO SENTIDO CENTRO/PERIFERIA, URBANO/RURAL, LOCAL/GLOBAL, PARTINDO DA LEITURA ANALÍTICA DE DOIS ROMANCES DAS LITERATURAS AFRICANAS DE LÍNGUA PORTUGUESA. ASSIM, O CORPUS LITERÁRIO E SUAS PREOCUPAÇÕES TEMÁTICAS SÃO PENSADOS À LUZ DAS CONTRIBUIÇÕES DA CRÍTICA TEÓRICA E METODOLÓLOGICA AO MODELO DE RACIONALIDADE OCIDENTAL: PRIMEIRO PELA SOCIOLOGIA DAS AUSÊNCIAS, E, SEGUNDO, PELA ECOLOGIA DE SABERES, COMO ENFOQUES REPRESENTATIVOS DO NOVO PARADIGMA DE TRABALHO, DESIGNADO POR EPISTEMOLOGIAS DO SUL.
\end{abstract}

ABSTRACT: THIS PAPER AIMS TO THINK HOW DISPLACEMENTS AND TRAVELLING ARE CREATORS OF MOVEMENT TOWARDS CENTER/PERIPHERY, URBAN/RURAL, LOCAL/ GLOBAL, FROM THE ANALYTICAL READING OF TWO AFRICAN NOVELS OF PORTUGUESE LANGUAGE. THEREFORE, WE TRIED TO THINK THE LITERARY CORPUS AND THE THEMATIC CONCERNS IN LIGHT OF THE CONTRIBUTIONS COMING FROM THE METHODOLOGICAL AND THEORETICAL CRITIQUE TO THE MODEL OF WESTERN RATIONALITY. FIRSTLY, FROM THE SOCIOLOGY OF ABSENCES, AND, SECONDLY, FROM THE ECOLOGY OF KNOWLEDGES, AS REPRESENTATIVE TOOLS OF THE NEW PARADIGM OF WORK DESIGNATED AS EPISTEMOLOGIES OF THE SOUTH.

PALAVRAS-CHAVE: MODERNIDADE, COLONIALIDADE, SOCIOLOGIA DAS AUSÊNCIAS, ECOLOGIA DE SABERES E EPISTEMOLOGIAS DO SUL. KEYWORDS: MODERNITY, COLONIALITY, SOCIOLOGY OF ABSENCES, ECOLOGY OF KNOWLEDGES, AND EPISTEMOLOGIES OF THE SOUTH. 
ara se aprender a partir do sul, devemos, antes de mais, deixar falar o Sul, pois o que melhor identifica o Sul é o facto de ter sido silenciado.

Boaventura de Sousa Santos (2002b, p.344)

\section{Itinerário teórico: modernidade, colonialidade e itinerários do 'Sul' em viagem}

Pensar o Sulé, antes de mais, reconhecer que "o Sul, tal como o Oriente, é um produto do império" (SANTOS, 2002b, p.340). A viagem da modernidade ocidental concebeu-se partindo de uma premissa: imaginar-se e projectar-se como centro. Sendo assim, o imaginário da modernidade do pensamento ocidental só foi possível quando se converteu numa força produtora de periferias e causadora incomparável da aniquilação e supressão de outras culturas e de outros saberes. Apoiando-se em sua tese sobre o "pensamento abissal", Boaventura Sousa Santos (doravante BSS) faz a seguinte observação: "a humanidade moderna não se concebe sem uma sub-humanidade moderna. A negação de uma parte da humanidade é sacrificial, na medida em que constitui a condição para a outra parte da humanidade se afirmar enquanto universal"' (Id., 2009:30-31).

Desse modo, a narrativa epistémica do mundo ocidental resultou na criação de duas cartografias humanas: por um lado, a cartografia do progresso, do desenvolvimento e da ciência, espelhada no Norte Imperial e, ainda hoje, no Norte Global Não-Imperial. Por outro lado, há a cartografia do Sul colonizado e subalterno e, actualmente, o Sul Global, como metáfora do sofrimento humano, da pobreza, do subdesenvolvimento, do atraso cultural, social e económico.

Walter Mignolo, nas suas mais recentes reflexões alerta para o facto de a modernidade, ou a sua retórica, não ter sido senão a concretização da ideia de que o mundo ocidental, para se sentir crível aos seus próprios olhos, tinha que conceber espaços externos subjugados a uma internalidade epistémica, para então imaginar-se como centro irradiador de pensamento, progresso, desenvolvimento e ciência. Desta maneira, a retórica da modernidade operaria de dentro para fora, e, de acordo com Mignolo, "through the imposition of 'salvation', whether as Christianity, civilization, modernization and development" (MIGNOLO, 2007a:463). 
Será, portanto, nessa produção perversa do Outro como inferior que a ideia do que é "tradicional", "primitivo", resulta como elementos constitutivos e representativos da modernidade. De tal forma que, o Outro como ser inferior, sem lei, sem cultura, torna-se o fulcro epistémico deste modelo de racionalidade ocidental. Por conseguinte, como esclarece perfeitamente Mignolo: "the 'outside' of tradition is invented in order to ensure the inside as the locus of enunciation of knowledge. 'Tradition' is not a way of life that predated 'modernity' but an invention of the rhetoric of modernity" (Ibid.:472).

Consequentemente, não será espúrio defender o argumento de que o modelo de racionalidade ocidental traz incrustada uma espécie de razão, a qual BSS denominou de razão metonímica. Segundo o autor, a razão metonímica obedece, na sua origem, aos impulsos da modernidade. Por um lado, ela é imaginada como um todo (centro) epistémico; portanto, orientada para uma visão limitada e limitadora do mundo. Logo, como espelho da retórica da modernidade, a razão metonímica "não é capaz de aceitar que a compreensão do mundo é muito mais do que a compreensão ocidental do mundo" (Idem, 2002a:242). E, ao proceder deste modo, rejeita, ignora e procura suprimir a inesgotável riqueza do mundo das experiências sociais (SANTOS, 2008).

Por outro lado, a razão metonímica é obstinada na sua postura de produzir binarismos em torno de uma ideia de totalidade. Como resultado, "o Norte não é inteligível fora da relação com o Sul, tal como o conhecimento tradicional não é inteligível sem a relação com o conhecimento científico ou a mulher sem o homem" (Id., 2002a:242). Reduzida a uma leitura espartilhada do mundo social, a razão metonímica não é mais do que uma epistemologia da cegueira do modelo de racionalidade ocidental (Id., 2002b), no que se refere ao reconhecimento da contemporaneidade e à co-existência de outros espaços e tempos culturais.

De facto, a retórica da modernidade apenas foi possível mediante a imposição de uma lógica da colonialidade, i. e. , enquanto a modernidade é imaginário e pensamento, a colonialidade é um seu capataz, a mão que controla e actua e, cegamente, traz para a vida real uma História plena de apropriação, exploração e violação. Para a lógica da colonialidade só a apropriação do espaço e tempo do Outro faz sentido, transformando a sua idiossincrasia ontológica e epistémica em rasura e vazio existenciais em face de uma obrigação de vassalagem e obediência a uma monocultura de saber ocidental. Como salienta Mignolo 
(2007a), o vocabulário da conquista na linguagem da retórica da modernidade torna-se o vocabulário da apropriação da terra, da exploração do trabalho, do controlo das subjectividades e do controlo do género e da sexualidade.

Nelson Maldonado-Torres $(2007,2008)$ chama a atenção para o facto de os discursos da modernidade terem esquecido a importância da localização geopolítica, no sentido em que o conceito de espacialidade é essencial para o melhor entendimento da relação entre a apropriação da terra e do trabalho, por um lado, e a hierarquização e racialização dos seres entre "superiores" e "inferiores, por outro. Ele observa que não era apenas de um racismo biológico que a modernidade abusava em seus discursos, mas, em simultâneo, de um racismo epistémico, muito mais virulento e ominoso, pois, a partir desse outro racismo evitava-se "reconhecer os outros como seres inteiramente humanos" (MALDONADO-TORRES, 2008:79).

Para o escopo do presente trabalho, penso serem relevantes as reflexões em torno dos conceitos de colonialidade do saber e do ser. Deste modo, entendo como incontornáveis as formulações teóricas que Maldonado-Torres tem trazido para uma visão contextualizada sobre o que é, por um lado, a colonialidade do ser, e, por outro lado, aquilo que o autor denomina por "esquecimento da colonialidade" (Ibid., 2008:73). Para o crítico, a colonialidade ultrapassa, na sua duração histórica e epistémica, a narrativa do colonialismo, sendo a colonialidade uma realidade que sobrevive ao colonialismo.

Maldonado-Torres (2008) e Mignolo (2003) mostram claramente este conúbio entre conhecimento e ser, a partir do qual se pode pensar na colonialidade do ser. Para Maldonado-Torres, a colonialidade do ser sugere que o SER, até certo ponto, refuta e contraria a "nossa própria existência", pois, no espaço e tempo dessa colonialidade, não se abre para o Ser "o reino da significação", mas algo que o procura anquilosar e aniquilar e, cujo alvo seria a violência ontológica, a supressão de outros saberes, e de outras cartografias identitárias.

$\mathrm{Na}$ opinião de BSS, "o reconhecimento da persistência do pensamento abissal é, assim, a condição sine qua non para começar a pensar e a agir para além dele" (SANTOS, 2009:44). Nesse sentido, retomando as reflexões de BBS, combater uma epistemologia da cegueira é promover o terreno fértil para a emergência de uma epistemologia de outros e alternativos conhecimentos, produzidos como ausentes e inexistentes (o que o sociólogo denomina por epistemologia dos conhecimentos e dos agentes ausentes (SANTOS, 2002b). 
Para combater essa cegueira, BSS propõe como instrumento metodológico a sociologia das ausências. Segundo ele, a estrutura programática desta nova proposta epistemológica procura libertar os diversos repertórios humanos e culturais existentes do estatuto de "resíduo". Deste modo, a sociologia das ausências transforma todos os conhecimentos e saberes, até então ausentes, em activamente presentes, contemporâneos e simultâneos.

Como ultrapassar essa acédia ocidental e epistemológica? Apostando numa ecologia dos saberes, que rejeita a existência de uma só epistemologia hegemónica e abissal da cartografia do mundo. Em essência, é uma postura epistémica que resulta da grande aposta que BSS e Paula Meneses designam como "epistemologias do Sul" (2009). Para ambos os estudiosos, as epistemologias do Sul têm como fulcro de suas preocupações dar conta "da diversidade epistemológica do mundo (...)" (Ibid.:12). Assim, os gestos de "aprender que existe o Sul", "aprender a ir para o Sul" e, "aprender a partir do Sul e com o Sul”, implicam viagens (grifo meu) e a validação gnosiológica e ontológica de outros saberes e de outras cosmogonias.

Mais do que presenças teóricas, as reflexões dos pensadores que formatam o contexto teórico deste ensaio, permitem colocar o dedo na ferida. Isto é, nas feridas e cicatrizes do passado colonial, da subalternidade e do silêncio, do exílio e da nostalgia. As linhas de pensamento aqui sistematizadas e analisadas permitem, por um lado, refutar a hegemonia e a fixidez inerentes ao pensamento Ocidental; por outro lado, permitem evidenciar a existência de outras narrativas ou outros modos de pensar a "nação" ontológica e cultural dos vários mundos sociais. No meu entender, partindo de um trabalho de leitura e análise comparativa, tanto João Paulo Borges Coelho, com Hinyambaan, quanto José Eduardo Agualusa, com Um estranho em Goa, realizam, como escritores e cidadãos do Sul, essa viagem ao Sul, com o Sul e através do Sul, com toda sua complexidade e multiplicidade de conhecimentos co-presentes.

\section{O norte do sul global em Hinyambaan ou o reconhecimento de uma ecologia de saberes}

$\mathrm{Na}$ actual cartografia literária das literaturas africanas de língua portuguesa, João Paulo Borges Coelho (doravante JPBC) tem sido uma das vozes que, 
a meu ver, traz para o Sul Global a análise de como o Sul continua, ainda, embebido da dualidade cultural entre Sul e Norte. Muito mais do que uma agenda ficcional, as obras deste escritor, cidadão do Sul Global, permitem ao leitor uma ponderada percepção da realidade africana, concedendo, assim, um enquadramento epistemológico no qual se torna visível, como observa BSS, que no Sul Global continuam a traduzir-se no quotidiano dos seus cidadãos imposições ideológicas e violências "de toda a espécie..., excepto no das elites que constituem o pequeno mundo do Sul imperial, a 'representação' do Norte global no Sul global" (SANTOS, 2008:17).

Mais do que uma visão idealizada do Sul enquanto repertório das emancipações políticas e independentistas que muitos países africanos puderam acrescentar à sua narrativa pós-colonial, Hinyambaan é a narrativa da ecologia de saberes, da tradução cultural entre diferentes cosmogonias; enfim, da perplexidade de que também o Sul tem valores e contribuições importantes para um melhor entendimento do mundo humano.

Com a elegância da sua esgrima literária, JPBC conduz o leitor numa viagem através do encontro de diferentes tempos culturais, epistemológicos, entre o mundo local (artesanal, comunitário e tradicional) personificado pelo irrequieto Djika-Djika, e um outro mundo humano funcionando como representação metonímica de um "Norte Global" no "Sul Global". Esse, retratado na pele dos turistas brancos sul-africanos a caminho de suas esmeradas férias em Moçambique, durante as quais os personagens projectam os estereótipos sociais - laivos de uma modernidade ocidental e postura colonial - quando entram contacto com outros saberes e outros 'seres'. Atente-se aos seguintes excertos de "Hinyambaan":

Não se perde nada em não visitar Mapiutou. Aquilo não é propriamente uma cidade, é antes um amontoado de lixo, assaltantes e polícias corruptos.

'Não é Mapiutou, é Maputo', diz o pequeno Hendrick. (COELHO, 2008:22)

Basta olhar em volta para ver que quase tudo isto é mato. Daqui para a frente é tudo assim, pelo menos foi o que me disseram. Não hão-de faltar galhos secos em Hinyambaan! 
Henrietta Odendaal também colheu as suas informações, está segura do que diz.

'Não é Hinyambaan ma, é Inhambane', diz o pequeno Hendrick do banco de trás.

'Ou isso’ (grifo meu) (Ibid.:11)

$\mathrm{Na}$ viagem que agora se enceta, Moçambique emerge retratado como espaço pobre e culturamente primitivo. É visto pelos turistas sul-africanos como lugar dos "coitadinhos", onde grassam as "fomes" e as "catástrofes", onde a postura do Norte Imperial/Global se torna bem presente na leitura que Henrietta Odendaal faz dos meninos que encontram no caminho para Hinyambaan/Inhambane:

Henrietta Odendaal benze-se discretamente. Fá-lo sempre que passa em frente a um cemitério.

'Coitadinhos', diz.

'Quem?', pergunta o marido, (...).

'Coitadinhos, quem?', insiste ele.

'Os miúdos. Aposto que se não vendem as flores que têm passarão fome em casa. Se calhar, até levam pancada dos pais por isso. (Ibid.:26)

Metonímia de uma modernidade, também em viagem, com sua arrogância de "centro" epistemológico, Hinyambaan surge como o leitmotiv narrativo para uma rápida percepção do Outro, revestido de estranhezas e, habitante de um mundo incompreensível no tempo e espaço, de uma visão hegemónica no Sul Global. Impregnando as suas observações desse outro-mundo com comentários satíricos, a família Odendaal personifica a mitologia do Ocidente como mensageiro de progresso, desenvolvimento e ciência. É no "olho" desta tempestade de mal-entendidos e imbróglios no "mundo" do Outro que surge Djika-Djika. Personagem do espaço communal e "primitivo", Djika-Djika apresenta-se como o futuro cicerone desta família até Inhambane. 
Antes do destino final, os Odendaal são recebidos pela comunidade de Djika-Djika, que os acolhe com a perplexidade não do Outro, mas, pelo contrário, como seres da terra estranhando e "outrocizando" os Odendaal: "Valungu! Valungu!', dizem como se cantassem" (Ibid.:56). Em contacto com uma outra cultura, com outras cosmogonias, os Odendaal ocupam o papel do elemento alienígena, confrontando-se e desafiando-se com outras dinâmicas sociais, outras linguagens de partilha e de solidariedade, e de organização social:

Henrietta Odendaal hesita, habituada que está a começar por um corpo limpo e congelado, plastificado, apanhando na prateleira climatizada de um supermercado, não por esta confusão de asas e penas jorrando sangue pelo pescoço. Mas logo se decide e parte lesta a buscar ao atrelado um frasco de compota de mirtilo, preciosidade que uma tia lhe enviou há tempos de Inglaterra: mostrará como se cozinha de verdade uma galinha! Regressa e apresenta o frasco, orgulhosa. A galinha untada com aquilo ficará uma delicía! (grifo meu).

Francisca Musweki pega no frasco, abre-o, mete o dedo dentro e prova. Faz uma careta de surpresa.

'É este o vosso piripiri?', pergunta. E solta uma ampla gargalhada (grifo meu)

As outras mulheres riem também, quando ela explica o que quase sucedia. A bandeiras despregadas. (Ibid.:63, veja-se p. 64-67)

É nesse encontro com o Outro que se apresenta o maior desafio epistemológico aos Odendaal. Subitamente, eles confrontam-se com o desaparecimento do seu filho mais novo. A ajuda para o resgate do menino vem de Vovó Thum; e dela emana aquela profunda cosmogonia que a modernidade reduziu ao lugar de superstição, primitivismo e irracionalidade. Apoiando-se no conhecimento ancestral de ler a natureza e seus fenómenos, Vovó Thum declara, para incredulidade dos sul-africanos, que o menino desaparecido é um menino que tem poderes especiais, que chama a chuva, e onde essa chuva poisar é lá onde se encontra o desaparecido:

1. Valungu (singular de mulungo), que significa brancos. 
Djika-Djika aproxima-se, baixa-se e ouve atentamente o que Vovó Thum tem a dizer.

'Que disse ela?', pergunta Henrietta Odendaal.

'Pede alguma coisa que pertença ao menino', responde ele.

'Vovó Thum diz que o menino foi por ali', responde Djika-Djika. 'Diz que não há que enganar. O menino é especial, tem poderes de chamar chuva: onde estiver molhado é onde está o menino esperando por nós!'

Poderes de chamar a chuva? Hermann Odendaal encolhe os ombros: nunca notou no filho esses poderes. (Ibid.:71-72)

Diante do impensável, o espectro da modernidade ocidental com a sua visão metonímica dos vários universos culturais é colocado em questão. Os seus mitos erigidos como leis universais são confrontados com a sua incompletude e imperfeição; pois, parafraseando BSS, "o saber que ignora é o saber que ignora os outros saberes que com ele partilham a tarefa infinita de dar conta das experiências do mundo" (SANTOS, 2008:27). Em Hinyambaan a realidade da ecologia dos saberes é posta à prova e, aplicada dentro dos seus limites, exerce-se como uma contribuição alternativa, complementar e simultânea e, enfim, é pensada como legítima e crível na construção do mundo, seja uma construção ontológica, cosmogónica ou gnosiológica.

\section{Pensar o sul global com o imaginário do norte imperial: a cartografia do exílio pós-colonial em Um estranho em Goa}

Em 2000, José Eduardo Agualusa publica Um Estranho em Goa (nova publicação em 2007, pela Biblioteca Editores Independentes). Cidadão e escritor do Sul (Angola, Portugal, Brasil: países que constituem uma trilogia toponímica de sua experiência subjectiva), José Eduardo Agualusa (doravante JEA) é também o escritor do entre-lugar. Desterritorializando-se por vários tipos do Sul Global, presentes ao longo de suas narrativas ficcionais, JEA apresen- 
ta neste texto, em viagem, paisagens humanas que revelam a complexidade e simultaneidade, não obstante antagónica, das identidades e cosmogonias presentes em Goa. Por uma opção de trabalho e respeitando os eixos teóricos aduzidos e analisados na primeira parte deste artigo, optei por focalizar minha atenção nos chamados descendentes luso-indianos, ou mestiços, como observa um dos personagens da diegese:

"Eles chamam-se a si próprios Descendentes", corrigiu-me Karmali quando lhe falei nisso, "nós chamamo-lhes mestiços". Na época colonial, segundo o presidente da Associação dos Combatentes pela Liberdade de Goa Damão e Diu, "esta gente era mais papista que o Papa. Queriam ser mais portugueses que os portugueses" (AGUALUSA, 2007:88-89, Grifo meu).

Enclausurados numa redoma de exílio pátrio e identitário que para muitos teve início com a invasão de Goa, em 17 de Novembro de 1961, a nostalgia pelo passado colonial e a fidelidade identitária e cultural ao seu colonizador espelham e mostram a sobrevivência da herança deixada pelo colonialismo português em Goa. No fundo, a herança de Portugal como a "do império como imaginação do centro":

- A senhora não é portuguesa?

Chorou:

- Sou portuguesa, sim, meu filho, no coração sou portuguesa. Mas obrigam-me a usar esta coisa.

A coisa era o passaporte. Os funcionários, conta ela, riram-se muito. Joaquim, o filho mais novo, assiste à conversa. É um sujeito alto, moreno, de cabelo lustroso. Percebe-se, ao contrário da mãe, que tem sangue indiano. Ele, como os quatro irmãos, nunca foi a Portugal. Mas também se sente português:

- Somos portugueses. Portugueses da Índia. Não temos nada a ver com esta gente. (Ibid.:65) 
Para estes goeses, Portugal representa, ainda, o esplendor da sua cartografia subjectiva, e a referência de serem filhos de um "deus"-colonizador maior:

O táxi de Sal também tem uma bandeira portuguesa, colada no vidro posterior, ao lado de outra da União Europeia. (Ibid.:21)

Perguntei-lhe de onde veio aquele nome, Sal, inédito para mim. Estaria à espera, na Índia, de encontrar alguém chamado, sei lá, Pimenta, Cravinho, até Açafrão, mas nunca Sal. A resposta deixou-me atordoado. Pedi-lhe para repetir e ele, dessa vez, disse-me o nome completo. Torce-o, porém, tão cruelmente, que só quando o vi escrito o compreendi - Salazar Barata de Sousa. Pergunteilhe se sabia quem foi Salazar. Sal olhou para mim ofendido:

- Um grande português. (grifos meus, Idem:24)

Um estranho em Goa, como uma epistemologia literária do Sul, permite-nos questionar se a lógica da colonialidade do saber e do ser podem ser pensadas como realidades pretéritas e anuladas por uma postura pós-colonial de resistência. No fundo, ao "viajar" com estes personagens, JEA reforça com sua escrita as observações assaz pertinentes e inquietantes que Maldonado-Torres dispôs da seguinte maneira: "Thus, coloniality survives colonialism" (grifo meu, 2007:243).

De facto, a narrativa leva-nos ao encontro de uma "modernidade" resistente, da localização de um Norte Imperial no olhar e identidades daqueles que no tempo e espaço do pós-colonialismo indiano vivem uma dupla subalternidade. Por um lado, subalternos e transformados num sub-Sul Global no interior de um Sul Global; e, por outro lado, subalternos e presos a essa colonialidade perversa do ser, que os faz olhar para o Outro-hindu com toda a mordacidade e sarcasmo que a retórica da modernidade, e a lógica da colonialidade, deixaram como legados de classificação dos seres, mediante a percepção vituperante das diferentes configurações culturais.

O trabalho de menosprezo do Outro perpassa toda a narrativa, no que toca à diversidade religiosa entre os goeses portugueses e, muito especificamente, os hindus. Atentemos à seguinte passagem do romance, realçando o conflito entre a modernidade e sua "arrogância" e outras manifestações religiosas percebidas como "resíduos", superstições, até mesmo como a personificação do ridículo: 
O meu motorista (há seis dias que ando com ele) odeia os hindus. "Se houver uma Guerra na Índia entre mouros e hindus", confidencia-me, e dir-se-ia interessado em que isso aconteça, "nós, os católicos, vamos apoiar os mouros". ... Tenho ao meu lado um guerreiro numa cruzada:

- Olhe bem para os deuses deles. Homens com cabeça de elefante, outros com cara de macaco, mulheres com seis braços, como as aranhas, é uma colecção de monstros! Não entendo como alguém pode adorar figuras assim. Agora olhe para a Nossa Senhora, tão linda, veja como a luz se desprende dela ...”. (grifo meu, AGUALUSA, 2007:21-22)

Como proposta de leitura de uma sociologia das ausências, Um estranho em Goa traduz a presença real e não ausente de um Sul Global - o território Indiano - sustentando em seu interior um sub-Sul Global, mas com imaginação, em si, de um Norte Imperial e Global. Deste modo, acredito ser plausível pensar esta "viagem" ao Sul como evocação metonímica de uma cartografia de vida e identidades sentida e percebida como estranha ${ }^{2}$ a este Goa arrancado às mãos do antigo poder colonial português. O "estranho em Goa", a meu ver, não é tanto o autor-narrador e personagem, mas, de forma mais precisa, todos os homens e mulheres goeses que guardam em si o fervor de uma perda e de um exílio no tempo e espaço do pós-colonialismo português.

\section{Considerações finais: "aprender a partir do Sul”}

Pensar o Sul pelo Sul na leitura da narrativa pós-colonial é um exercício de crítica ao modelo de pensamento ocidental. Esta seria uma conclusão óbvia. Contudo, as leituras analítica e comparativa dos romances abordados no presente trabalho serviram, em primeiro lugar, como uma ponte de diálogo entre teoria e prática, tendo em conta que a realidade do mundo humano neles apresentada é uma realidade ficcional. Em segundo lugar, o enfoque comparativo/analítico entre as diegeses aduzidas e estudadas revela que o Sul Glo-

2. Essa estranheza encontra a sua corporalidade na voz e desabafo de um dos personagens: "Cada dia nos sentimos mais estrangeiros dentro da nossa própria terra” (AGUALUSA, op. cit., p.116, grifo meu,). 
bal é também um espaço de ambiguidades, ambivalências e abismos culturais. De tal modo, não é possível meramente sustentar a ideia "paradisíaca" do Sul como espaço geopolítico da inscrição das narrativas de resistência colonial e de emancipação política, no que toca à longa história das feridas coloniais abertas e impostas por uma insidiosa retórica da modernidade/colonialidade.

O Sul Global é, isto sim, um universo onde, ainda nos dias actuais, se vivenciam subalternidades atrozes e complexas, que não podem fugir ao um olhar realista sobre o mundo das experiências humanas no Sul Global. Desta maneira, a riqueza encontrada nas viagens até Hinyambaan e Goa demonstram, por um lado, a diversidade epistemológica co-presente no Sul Global - pensando nestas narrativas como instrumentos de trabalho que subjazem a uma sociologia "literária" das ausências e, em simultâneo, trazendo à luz da discussão dos problemas do mundo o que em muitos momentos poderá ser produzido como ausente.

Por outro lado, enquanto em Um estranho em Goa se faz uma discussão ficcional de uma sociologia dos agentes ausentes, no romance de JPBC o alcance dessa sociologia é bem mais patente e "visível". Isso se dá pelo modo como os registos ficcionais ilustram a credibilidade da construção cognitiva mediante uma ecologia de saberes, e pelo modo benéfico como esta "ecologia" assume a cartografia de uma hermenêutica do mundo e das suas verdades. Pois, no final destas viagens ao "Sul" percebemos que não existem verdades epistémicas absolutas, mas, pelo contrário, complementares, simultâneas e contemporâneas no tempo e espaço, seja do Norte Global, seja do Sul Global.

\section{Referências Bibliográficas}

AGUALUSA, Eduardo. Um Estranho em Goa. Lisboa: Biblioteca Editores Independentes, 2007.

COELHO, João Paulo Borges. Hinyambaan. Lisboa: Editorial Caminho, 2008.

MALDONADO-TORRES, Nelson. A topologia do Ser e a geopolítica do conhecimento. Modernidade, império e colonialidade. In Revista Critica de Ciências Sociais, 80:71-114, março, 2008.

. On The Coloniality of Being. Contributions to the Developemnt of a concept. In Cultural Studies, vol. 21(2-3): 240-270, march/may, 2007.

MIGNOLO, Walter. Deliking. In Cultural Studies, vol. 21:(2-3): 449-514, march/may, $2007^{\mathrm{a}}$. 
Epistemic disobedience: the de-colonial option and the meaning of identity in politics. In Revista Gragoatá, Niterói: n. 22: 11-41, 2007 b.

- Os esplendores e as misérias da 'ciência': Colonialidade, geopolítica do conhecimento e pluri-diversidade epistémica. In SANTOS, Boaventura de Sousa (org. ). Conhecimento prudente para uma vida decente: Um discurso sobre as ciências'revistado. Porto: Edições Afrontamento, 2003:631-672.

SANTOS, Boaventura de Sousa e MENESES, Maria Paula (orgs. ), Epistemologias do Sul. Porto: Edições Afrontamento, 2009.

Para uma sociologia das ausências e uma sociologia das emergências. In Revista Critica de Ciências Sociais, 63:237-280, outubro, 2002a.

- A Critica da Razão Indolente - Contra o desperdício da experiência. Porto: Edições Afrontamento, 2. edição, 2002b.

- A filosofia à venda, a douta ignorância e a aposta de Pascal. In Revista Critíca de Ciências Sociais, 80:11-43, marco, 2008.

Para além do pensamento abissal: Das linhas globais a uma ecologia de saberes. In SANTOS, Boaventura de Sousa e MENESES, Maria Paula (orgs.). Epistemologias do Sul. Porto: Edições Afrontamento, 2009:23-71.

Recebido em 06 de Abril e aprovado em 10 de maio de 2010. 